\title{
Propriedade Intelectual, Registro e Transferência de Tecnologia: Estudo de Caso de cultivares de aveia da Universidade Federal do Rio Grande do Sul (UFRGS)
}

\author{
Intellectual Property, Registration and Technology Transfer: Case Study \\ of oat varieties from the Federal University of Rio Grande do Sul \\ (UFRGS)
}

\author{
Patrícia Ziomkowski ${ }^{1}$ \\ Kelly Lissandra Bruch ${ }^{2}$ \\ Giandra Volpato ${ }^{1}$ \\ ${ }^{1}$ Instituto Federal de Educação, Ciência e Tecnologia do Rio Grande do Sul, Porto Alegre, RS, Brasil \\ ${ }^{2}$ Universidade Federal do Rio Grande do Sul, Porto Alegre, RS, Brasil
}

\begin{abstract}
Resumo
A proteção de novas variedades vegetais é pouco explorada pela literatura, embora seja fundamental ao agronegócio. Estudos sobre essa modalidade de propriedade intelectual são relevantes para sua melhor compreensão. Assim, o artigo analisa a proteção, o registro para a produção e comercialização e a transferência de tecnologia das cultivares de aveia da UFRGS a partir de estudo de caso do Programa de Melhoramento Genético de Aveia da Universidade. Como resultados, verifica-se que os melhoramentos da aveia contribuíram para a adaptação às condições de clima $e$ ao solo brasileiro, a precocidade do ciclo de plantio, o maior rendimento e a qualidade industrial. Quanto à proteção $e$ ao registro das cultivares, observa-se que as rotinas estão consolidadas pelos próprios melhoristas do Programa. $\mathrm{Na}$ área de transferência de tecnologia, contudo, identificam-se possibilidades de atuação em prospecção tecnológica, inteligência competitiva e delineamento de ações de marketing comercial para a divulgação das cultivares.
\end{abstract}

Palavras-chave: Proteção de Plantas. Melhoramento de Plantas. Novas Variedades Vegetais.

\begin{abstract}
The protection of new varieties of plants is poorly explored in the literature, although it is fundamental to agribusiness. Studies about this modality of intellectual property are relevant for its better understanding. Thus, the article analyzes protection, registration for the production and commercialization and technology transfer of UFRGS oat varieties, based on a case study of the University's Oat Breeding Program. As a results, it can be verified that the oats breeding contributed to the adaptation to the Brazilian climate and soil conditions, the precocity of the planting cycle, the highest yield and the industrial quality. Regarding the protection and the varieties' registration, it is observed that the routines are consolidated by the own Program's breeders. In the area of technology transfer, however, possibilities for action in technological prospecting, competitive intelligence and the design of commercial marketing actions for the dissemination of cultivars are identified.
\end{abstract}

Keywords: Plant Protection. Plant Breeding. New Varieties of Plants.

Área Tecnológica: Propriedade Intelectual. Proteção de Novas Cultivares. 


\section{Introdução}

O melhoramento genético de plantas contribui para o incremento do setor agrícola, proporcionando o aumento da produtividade das espécies, a maior resistência às pragas, a adaptabilidade ao clima e ao solo, a produção na entressafra, além de aprimorar a própria qualidade da variedade (CARMO et al., 2019). Estudos nesse ramo perduram por 8 a 12 anos, para espécies anuais, e de 20 a 30 anos para variedades perenes, demandando investimentos em terras, instalações, como estufas e casas de vegetação, laboratórios e mão de obra qualificada e multidisciplinar (CUNHA, 2011).

Como medida de estímulo a novas pesquisas na área, acordos internacionais e legislações nacionais passaram a disciplinar sistemas de apropriação intelectual de cultivar, definida como variedade cultivada de planta resultante de técnicas de melhoramento que alteram os seus atributos originais (JUK; FUCK, 2020a). A proteção de cultivar tem por objetivo assegurar a apropriabilidade dos esforços inovativos sobre uma nova variedade de planta ao seu obtentor, para que este tenha retorno financeiro dos investimentos empregados no melhoramento vegetal. Dessa forma, uma vez concedida a proteção, durante a sua vigência, veda-se que terceiros, sem a autorização do titular do direito sobre o bem intangível, produzam para fins comerciais, ofereçam à venda ou comercializem o material propagativo da cultivar (JUK; FUCK, 2020b; AVIANI; MACHADO, 2015).

No Brasil, a proteção de novas cultivares é disciplinada pela Lei n. 9.456/1997, denominada Lei de Proteção das Cultivares (LPC), e pelo Decreto n. 2.366/1997, que dispõe sobre o Serviço Nacional de Proteção de Cultivares (SNPC), órgão vinculado ao Ministério da Agricultura e do Abastecimento (MAPA) e competente para a proteção de cultivares no país (BRASIL, 1997a; 1997b). Em linhas gerais, para que sejam passíveis de proteção, as novas variedades vegetais devem resultar de intervenção humana, apresentar denominação única e apropriada e observar os requisitos técnicos da distinguibilidade, homogeneidade e estabilidade (AVIANI; MACHADO, 2015). De acordo com a LPC, serão: 1) distintas, quando se diferenciarem de qualquer outra de existência reconhecida no momento do pedido de proteção; 2) homogêneas, quando os descritores que a identifiquem apresentarem variabilidade mínima no plantio em escala comercial; $e$ 3) estáveis, quando as características forem preservadas na reprodução para comercialização, mantendo a homogeneidade em gerações sucessivas. Ainda, devem apresentar novidade comercial, reputando-se novas quando não tiverem sido oferecidas à venda ou comercializadas, no Brasil, há mais de 12 meses da data do pedido de proteção ou, em outros países, há mais de seis anos (árvores ou videiras) ou mais de quatro anos (demais espécies) (BRASIL, 1997b).

Concedido o Certificado de Proteção de Cultivar pelo SNPC, são garantidos ao titular os direitos de propriedade intelectual sobre a nova variedade vegetal. Não obstante, para a produção e a comercialização do material propagativo, no Brasil, é necessária a inscrição da cultivar, seja ela protegida ou não, no Registro Nacional de Cultivares (RNC), também vinculado ao MAPA e disciplinado pela Lei de Semente e Mudas (LSM), Lei n. 10.711/2003, e pelo Decreto n. 10.586/2020, que a regulamenta (BRASIL, 2003; 2020; LEITE; CAMPOS, 2011). Para a inscrição, a depender da espécie, são exigidos ensaios de demonstração do Valor de Cultivo e Uso (VCU) ou ensaios de adaptação, a fim de comprovar o valor agronômico da variedade a ser registrada (BRUCH; DEWES; VIEIRA, 2015). 
Salienta-se que o direito de exclusividade para a exploração da cultivar pode ser exercido diretamente pelo seu titular ou por terceiros autorizados, mediante o recebimento de contraprestação (royalties) ou não. É possível que esse bem imaterial seja objeto de contratos de transferência de tecnologia, seja por meio de cessão temporária de direitos, denominada licenciamento, ou de cessão definitiva, nos casos de alienação do direito patrimonial (ROOIJEN, 2011).

Apesar de presente no nosso cotidiano, visto que a maior parte da alimentação decorre do consumo de sementes e vegetais, existe pouca produção da literatura sobre a proteção de novas variedades de plantas em comparação a outras áreas da propriedade intelectual (CORDEIRO; ROMEIRO, 2020). Ademais, estudos analisando casos de transferência de tecnologia de cultivares, fundamentais ao agronegócio, são relevantes para sua melhor compreensão. Assim, tecidas tais considerações, o presente artigo pretende explorar como ocorre a proteção, o registro e a transferência de tecnologia das cultivares obtidas pelo Programa de Melhoramento Genético de Aveia da Universidade Federal do Rio Grande do Sul (UFRGS). Para tanto, a partir de pesquisas documental e bibliográfica, foram examinados os aspectos legais e técnicos necessários para o requerimento do direito de exclusividade e o registro para produção e comercialização de cultivares no Brasil, além de questões relativas à exploração desse ativo intangível. Ainda, realizou-se pesquisa exploratória, delineada na forma de um estudo de caso sobre a experiência do referido Programa.

O grupo de pesquisa em melhoramento genético de aveia da Faculdade de Agronomia da UFRGS iniciou em 1974. Anteriormente aos resultados obtidos pelo Programa, o Brasil importava sementes de aveia para o abastecimento do mercado interno, mantendo uma área territorial de plantio reduzida. A partir de processos de aprimoramento de características do cereal, com o intuito de adaptá-lo ao clima e ao solo brasileiro, foi possível a transformação da aveia de uma planta destinada à forragem em espécie produtora de grãos de alta qualidade para o consumo. Tal fenômeno proporcionou o aumento significativo na área de cultivo das sementes licenciadas pela Universidade e, por conseguinte, tornou o país autossustentável na produção da variedade (UFRGS, 2018).

A aveia apresenta diversas funções, podendo ser destinada à produção de grãos para a alimentação humana e/ou animal, em especial de cavalos de corrida, gado de leite e de corte; matéria-prima para a indústria química e de cosméticos e, mais recentemente, para a fabricação de etanol; forragem (pastejo, feno, silagem); cobertura do solo e adubação verde, visando a proteger as condições do solo e a implantação das culturas de verão; inibição de plantas invasoras pelo efeito alelopático e melhora do solo, uma vez que é imune às doenças causadas por fungos do trigo (FEDERIZZI et al., 2014; SÁ, 1995). É uma cultura de clima temperado, exigente de muita água e baixas temperaturas, mas que, por meio de melhoramento genético, pode ser adaptada ao cultivo em regiões de clima tropical e subtropical. Por apresentar invernos chuvosos, os Estados do Rio Grande do Sul e do Paraná destacam-se como os maiores produtores de aveia no Brasil, seguidos de Santa Catarina, Mato Grosso do Sul e São Paulo (PRIMAVESI; RODRIGUES; GODOY, 2000). As principais aveias cultivadas são das espécies aveia branca (Avena sativa L.), aveia amarela (Avena byzantina Koch) e aveia preta (Avena strigosa Schreb), com características fenotípicas e agronômicas diferentes. Devido à maior aptidão de produção de grãos, a Avena sativa L. representa cerca de $80 \%$ da área mundial cultivada com aveia (FEDERIZZI et al., 2014). 
Apesar das diversas funções que podem ser obtidas pelo uso da aveia, observa-se um decréscimo da área cultivada em comparação às commodities tradicionais de soja e milho, não apenas no Brasil, mas em outros países da América do Sul. Por consequência, verifica-se uma redução nas pesquisas e nos investimentos na cultura (FEDERIZZI et al., 2014). Assim, a partir da experiência da UFRGS em melhoramento genético da aveia, tendo como foco a análise da apropriação intelectual, do registro e da transferência de tecnologia dessas cultivares, o estudo pretende difundir a gestão desse ativo intangível e estimular os desenvolvimentos na área. A seguir, serão apresentados os procedimentos metodológicos e a análise dos resultados obtidos.

\section{Metodologia}

Buscando analisar como ocorre a proteção, o registro e a transferência de tecnologia das cultivares de aveia da UFRGS, realizou-se uma pesquisa de abordagem qualitativa e de cunho exploratório, delineada na forma de estudo de caso da experiência do Programa de Melhoramento Genético de Aveia da UFRGS. O método adotado visa a estudar com profundidade poucos ou apenas um objeto, a partir da coleta de dados reais, de modo a possibilitar o seu detalhamento, sem desvinculá-lo do seu contexto (GIL, 2017). Para a compreensão da temática, foram realizadas pesquisas bibliográfica e documental, na legislação nacional, nos regulamentos da Universidade e em documentos do Núcleo de Inovação Tecnológica (NIT) da UFRGS, além de informações constantes na Plataforma CultivarWeb. Após, realizou-se uma entrevista telepresencial, de caráter semiestruturado, com Engenheiro Agrônomo, Professor e melhorista do Programa, visando ao aprofundamento teórico de situações que emergem espontânea $e$ contingencialmente na prática profissional. A fim de garantir o seu anonimato, na apresentação dos resultados, este será identificado como Entrevistado. O participante assinou o Termo de Consentimento Livre e Esclarecido (TCLE), anuindo, também, com a gravação da entrevista, e a pesquisa foi dispensada do registro e da avaliação pelo Comitê de Ética em Pesquisa, conforme prevê o artigo $1^{\circ}$, § único, inciso VII, da Resolução n. 510/2016 do Conselho Nacional de Saúde (CNS, 2016). O roteiro de entrevista foi estruturado de forma a abranger perguntas sobre o Programa de Melhoramento Genético de Aveia da UFRGS, a proteção junto ao SNPC, o registro no RNC, a exploração e a gestão das cultivares de aveia da Universidade. As respostas foram classificadas em categorias descritivas para a melhor interpretação das informações, sistematizando-se as percepções do participante acerca dos temas questionados. Os dados foram examinados pela técnica da análise de conteúdo temática, a fim de inferir aspectos intrínsecos na comunicação do entrevistado (MINAYO, 2009). Com base na análise da entrevista e do referencial teórico, a seguir serão apresentados os resultados e a discussão.

\section{Resultados e Discussão}

Para a melhor exposição dos achados, a presente seção está categorizada da seguinte forma: Programa de Melhoramento Genético de Aveia da UFRGS; Proteção de cultivares de aveia da UFRGS; Registro de cultivares de aveia da UFRGS; e Transferência de tecnologia de cultivares de aveia da UFRGS. 


\subsection{Programa de Melhoramento Genético de Aveia da UFRGS}

De acordo com o Entrevistado, o Programa iniciou em 1974, na Faculdade de Agronomia da UFRGS, após o retorno de um dos seus pesquisadores do doutorado realizado na Universidade da Califórnia, Estados Unidos, trazendo linhas puras e segregantes de aveia para serem adaptadas ao clima e ao solo do Brasil. Inicialmente, o grupo de pesquisa era reduzido, tendo em vista que os estudos de melhoramento de plantas eram direcionados à cultura do trigo. Atualmente, participam dois melhoristas/docentes e cinco alunos por ano, entre cursos de graduação, mestrado e doutorado.

Um dos principais marcos do Programa foi a participação no projeto internacional Quaker International Oat Nursery (QION), financiado, primeiramente, pelo U.S. Department of Agriculture (USDA) e após pela Quaker Oats Company, reconhecida empresa processadora de aveia, cujo objetivo era promover a adaptação de aveia em diferentes regiões no mundo. Até 1982, as primeiras cultivares obtidas, denominadas URS 1 e URS 2, originaram-se de materiais vindos do exterior. Em 1986, passaram a ser realizados cruzamentos de material estrangeiro e brasileiro nos laboratórios da UFRGS. Essas variedades não apresentavam uma grande expressão das características. Contudo, a partir da URS 7 e da URS 14 em diante, notou-se uma melhor qualidade nas espécies desenvolvidas pela UFRGS em comparação a outras no mercado.

As diferenças de gerações das aveias melhoradas pela Universidade resumem-se a três enfoques: redução do tempo de plantio, melhoria na adaptação da espécie às variações ambientais e garantia de qualidade industrial dos grãos. Entre as décadas de 1970 e 1980, as primeiras cultivares obtidas, com materiais originários da Argentina e dos Estados Unidos, eram destinadas à forragem e apresentavam um ciclo muito longo, pois semeadas em junho e colhidas somente em dezembro. Dessa forma, não atendiam às demandas dos agricultores em razão da incompatibilidade com o plantio da soja, nos meses de outubro e novembro. Por essa razão, como primeiro enfoque, buscou-se encurtar o tempo de plantio da aveia, introduzindo gene canadense que reduziu o tempo total em 40 dias. Após, a partir de nova seleção no material, com introdução de outro gene, o ciclo tornou-se precoce, de junho a outubro.

Essa redução possibilitou a exploração de uma cultura de inverno rentável pelos agricultores, conciliando a aveia com outras espécies por meio do sistema de rotação de culturas. Além disso, quando plantada durante o outono e o inverno, favorece as propriedades físicas e químicas do solo, servindo como cobertura para protegê-lo da erosão e de outras condições prejudiciais antes da implantação da soja e do milho e reduzindo a presença de plantas daninhas, pragas e doenças em campo. Na Região Sul do Brasil, considerando a interligação da lavoura com a pecuária, costuma-se semear cultivares de aveia logo após a colheita das culturas de verão, entre os meses de março a maio, para fins de pastejo de animais e a colheita de grãos do rebrote (FEDERIZZI et al., 2014). Segundo o Entrevistado, com a intenção de aproximar-se da realidade dos agricultores, o Programa adota essa mesma logística e o plantio direto nos ensaios realizados na Estação Experimental Agronômica da UFRGS: semeia a aveia branca no inverno; a soja no verão; a aveia preta e o milho, respectivamente, no inverno e verão seguintes.

Com base em estudos de genética, identificou-se, também, a necessidade de outra adaptação na aveia para a remoção de gene de sensibilidade ao fotoperíodo, ou seja, ao tempo de exposição à luz que as plantas recebem por dia. Antes dos processos de melhoramento genético, independentemente da época do plantio, o florescimento da aveia só iniciava em outubro, quando 
há maior incidência solar, em razão da característica de fotoperíodo longo. Com a eliminação desse gene, foi possível antecipar esse fenômeno, o que contribuiu para a precocidade do ciclo.

No segundo momento do Programa, o enfoque passou a ser a adaptação da espécie às variações ambientais. Diferentemente do plantio nas regiões de clima temperado, em que há previsibilidade das condições climáticas, nas tropicais e subtropicais, há uma grande variação de temperaturas, quantidade de chuvas e incidência solar, as quais influenciam nos resultados do melhoramento. Somente com os anos de estudos, o Programa acumulou genes de adaptação à variação. Assim, por exemplo, é possível que uma mesma variedade seja plantada no Paraná, em abril, e no Rio Grande do Sul, em julho, obtendo-se os mesmos rendimentos. Além das interferências ambientais, o aprimoramento da resistência às doenças também foi objeto de pesquisas, a fim de proporcionar melhor qualidade e reduzir os custos de produção ao agricultor.

Nos últimos anos, os esforços do Programa são destinados a garantir a qualidade industrial, adaptando as cultivares para que revertam na maior quantidade de produtos processados pela indústria. Como exemplo, o Entrevistado cita a melhoria do descasque dos grãos, independentemente do tipo de tecnologia utilizado pelo agricultor, minimizando a ocorrência de quebras, que são descartadas na produção de flocos de aveia. Com esse aprimoramento, identificou-se um aumento no rendimento industrial, equiparado ao dos Estados Unidos, Canadá e Austrália.

De fato, a partir dos processos de melhoramento genético, foi possível obter sementes de alta qualidade, suprindo as demandas do mercado interno (UFRGS, 2020). Conforme apontam Federizzi et al. (2014), citando dados do IBGE de 2014, a área de cultivo de aveia no Brasil quintuplicou entre as décadas de 1970 e 2000, passando para a produção de 58 mil toneladas no final dos anos de 1970 para 516,5 mil toneladas do cereal na safra de 2005. Nesse sentido, também se verificou a ampliação na área de cultivo de sementes licenciadas pela UFRGS e no número de licenças aos produtores de sementes, totalizando mais de $90 \%$ das sementes comercializadas no Brasil (UFRGS, 2018).

Tais dados corroboram as mudanças econômicas ocorridas, a partir da metade do século $\mathrm{XX}$, no setor agroindustrial, que passa a substituir as importações de sementes e de insumos por apropriação de conhecimentos e transferência de tecnologia (SANTOS, 2012). Além da ampliação da produção, houve uma redução dos custos de cultivo e o surgimento de novos negócios, como as pequenas empresas processadoras de grãos, proporcionando emprego e renda para as comunidades locais, principalmente no interior da Região Sul do Brasil (FEDERIZZI et al., 2014; UFRGS, 2020).

\subsection{Proteção de Cultivares de Aveia da UFRGS}

Com a publicação da LPC, o Programa passou a tratar das questões relacionadas à propriedade intelectual desses ativos, tendo em vista que, antes da legislação, as sementes eram distribuídas de forma gratuita aos produtores. A primeira cultivar protegida foi a URS GUAPA em 2004. Desde então, todas as novas variedades de aveia obtidas são protegidas. As denominações das cultivares também foram substituídas por números para termos da Região Sul 
do país. Atualmente, a UFRGS é titular de 12 Certificados de Proteção de Cultivares de aveia, cuja relação é apresentada no Quadro 1 (MAPA, 2021).

Quadro 1 - Certificados de proteção de cultivares de aveia (Avena sativa L.) de titularidade da UFRGS vigentes, com a denominação, o número e os respectivos prazos de duração

\begin{tabular}{|c|c|c|c|}
\hline Denominação & $\begin{array}{c}\text { Número do CERTIFICAdo de ProteÇão } \\
\text { DE CULTIVAR }\end{array}$ & INícIo DA PROTEÇÃo & Término DA PROTEÇÃo \\
\hline URS Tarimba & 20110001 & $25 / 06 / 2010$ & $25 / 06 / 2025$ \\
\hline URS Taura & 20110002 & $25 / 06 / 2010$ & $25 / 06 / 2025$ \\
\hline URS Charrua & 20120030 & $02 / 08 / 2011$ & $02 / 08 / 2026$ \\
\hline URS Guria & 20120031 & $02 / 08 / 2011$ & $02 / 08 / 2026$ \\
\hline URS CORONA & 20120228 & $03 / 05 / 2012$ & $03 / 05 / 2027$ \\
\hline URS ESTAMPA & 20120230 & $03 / 05 / 2012$ & $03 / 05 / 2027$ \\
\hline URS GUARÁ & 20120227 & $03 / 05 / 2012$ & $03 / 05 / 2027$ \\
\hline URS TORENA & 20120232 & $03 / 05 / 2012$ & $03 / 05 / 2027$ \\
\hline URS Brava & 20150099 & $19 / 12 / 2014$ & $19 / 12 / 2029$ \\
\hline URS ALTIVA & 20160023 & $18 / 08 / 2015$ & $18 / 08 / 2030$ \\
\hline URS F Flete & 20170172 & $23 / 01 / 2017$ & $23 / 01 / 2032$ \\
\hline URS MONARCA & 20200142 & $22 / 01 / 2020$ & $22 / 01 / 2035$ \\
\hline
\end{tabular}

Fonte: Elaborado pelas autoras deste artigo (2021)

Cumpre salientar que a UFRGS também é obtentora da proteção de cultivares de lótus (URS BRS POSTEIRO), trevo branco (BRS URS ENTREVERO) e trevo vermelho (URSBRS Mesclador) em cotitularidade com a Empresa Brasileira de Pesquisa Agropecuária (EMBRAPA) (MAPA, 2021). Tais cultivares, contudo, estão fora do escopo de análise do presente estudo, uma vez que tratam de espécies diversas da aveia.

No âmbito da Universidade, as cultivares são disciplinadas pelas Portarias n. 349/2002 e n. 493/2002, ambas da Reitoria, e pela Decisão n. 16/2019 do Conselho Universitário, que instituiu a Política de Inovação da UFRGS (UFRGS, 2002a; 2002b; 2019). Segundo o Entrevistado, é a única universidade com regulamentações específicas sobre a matéria, as quais foram objeto de ampla discussão pelos órgãos competentes para a aprovação.

A Portaria n. 349/2002 da UFRGS estabelece as regras para a proteção das cultivares. Determina que a Universidade terá a propriedade exclusiva e a titularidade sobre toda a cultivar obtida em programas de melhoramento genético da instituição. Admite, contudo, o regime de cotitularidade com terceiros, desde que haja colaboração no planejamento, financiamento ou condução do projeto de pesquisa, com definição das responsabilidades de cada entidade, e a celebração de um contrato ou termo de cooperação técnica entre a Universidade e o parceiro (UFRGS, 2002a). 
Ademais, define como melhoristas os docentes e técnicos com formação na área e que tenham contribuído por, no mínimo, seis anos para a pesquisa ou o desenvolvimento aprovado pelas instâncias da UFRGS ou no caso de o estudo ter sido conduzido com o emprego de recursos, dados, meios, informações ou equipamentos da instituição ou durante o horário de trabalho. Veda-se a apropriação de material genético vegetal da Universidade por servidor ou partícipes do projeto, sob pena de responsabilização civil e criminal. O cadastro de melhoristas deve ser mantido pelos programas, encaminhando-se cópia ao NIT (UFRGS, 2002a).

Nos instrumentos jurídicos com o objetivo de pesquisa e desenvolvimento, as cláusulas reguladoras de proteção de cultivares são obrigatórias. Ademais, antes da publicação dos resultados de estudos referentes às novas variedades vegetais desenvolvidas pela Universidade, devem ser adotadas todas as providências para a obtenção do privilégio. Eventual utilização de material biológico de outras instituições, bem como a cessão de material de propriedade da UFRGS para fins de pesquisa, deverão ser objeto de acordos de transferência entre as partes (UFRGS, 2002a).

Por sua vez, a Portaria n. 493/2002 da UFRGS regulamenta o desenvolvimento, a aplicação e a comercialização de plantas transgênicas, originadas de técnicas de engenharia genética. Por envolver organismo geneticamente modificado, exige-se a autorização, o cadastro e o acompanhamento pela Comissão Técnica Nacional de Biossegurança (CTNBio), em observância à Lei de Biossegurança. A cultivar transgênica poderá decorrer de gene patenteado pela UFRGS ou por terceiro, hipótese em que deverá ser firmado o prévio licenciamento com o titular do direito de exclusividade (BRASIL, 2005; UFRGS, 2002b).

A proteção de novas cultivares é requerida de forma eletrônica via Plataforma CultivarWeb do SNPC/MAPA. O formulário é preenchido pelos melhoristas do Programa, após a elaboração dos Testes de Distinguibilidade, Homogeneidade e Estabilidade (DHE), necessários para a comprovação dos requisitos técnicos. No Brasil, esses ensaios são conduzidos pelos próprios melhoristas/obtentores e seguem os procedimentos e os descritores mínimos divulgados pelo SNPC para cada espécie (MACHADO, 2011). Essas diretrizes são aplicadas por todos os Estados-signatários da União para a Proteção das Obtenções Vegetais (UPOV) e objetivam assegurar a harmonização internacional na condução e na avaliação das testagens, com a obtenção de resultados confiáveis e comparáveis, embora realizados em locais e por técnicos e/ou instituições diversas (MACHADO; SANTOS, 2011; AVIANI, MACHADO, 2015). Os Testes de DHE das cultivares de aveia da Universidade são realizados pelos melhoristas do Programa, na Estação Experimental Agronômica da UFRGS, localizada em Eldorado do Sul/RS. Trata-se de local onde são promovidas atividades de extensão universitária, a exemplo de dias de campo, visitas técnicas, cursos para a comunidade interna e/ou externa, além do desenvolvimento de cultivares e da realização de ensaios para fabricantes de máquinas agrícolas (UFRGS, 2021).

As instruções oficiais do SNPC para a execução de Testes de DHE de cultivares de aveia exigem, entre outras condições: 1) inclusão de, no mínimo, 2.000 plantas no ensaio, em densidade normal de semeadura, divididas em duas ou mais repetições, conduzido em condições para o desenvolvimento normal das plantas; 2) avaliação de, no mínimo, 100 fileiras, se conduzidos exames de panículas por fileira; 3) ensaios realizados por, no mínimo, dois períodos similares de cultivo; 4) conduzidos na mesma área experimental e na mesma época de semeadura, podendo ser avaliada alguma característica importante em local adicional; 5) observações para distinguibilidade e estabilidade em, no mínimo, 20 plantas ou partes de plantas; 6) realização 
de avaliações adicionais para fins especiais; 7) nas avaliações visuais da homogeneidade, o número máximo de plantas ou partes de plantas atípicas será de 5 em 2.000; 8) nas avaliações visuais da homogeneidade das características em panículas por fileiras, o número de fileiras com plantas ou partes de plantas atípicas será de, no máximo, 3 em 100 (MAPA, 2002).

Durante o período de proteção, que é 15 anos para a espécie de aveia, o titular do direito de exclusividade deverá manter amostra viva da cultivar protegida, bem como apresentá-la ao SNPC, no prazo de 60 dias da notificação, sob pena de ter cancelado o certificado de proteção. Para essa espécie, conforme mostram as diretrizes do MAPA, 1 kg de sementes deverá ser apresentada ao SNPC como amostra de manipulação e $1 \mathrm{~kg}$ de sementes como germoplasma, ficando o obtentor responsável por manter $1 \mathrm{~kg}$ de sementes (BRASIL, 1997b; MAPA, 2002).

A proteção de cultivar garante os direitos de propriedade intelectual sobre a nova variedade, contudo não habilita para a produção e a comercialização do material propagativo no Brasil, para o qual é necessária a inscrição no RNC, a ser tratada na próxima seção (LEITE; CAMPOS, 2011).

\subsection{Registro de Cultivares de Aveia da UFRGS}

Diferencia-se a proteção de cultivares, prevista na LPC, com finalidade de assegurar a exclusividade sobre o uso do material propagativo da espécie e garantir que o titular do bem imaterial possa licenciar, ceder e impedir a utilização sem a sua permissão, do registro, disposto na LSM, para fins de produção e comercialização das cultivares, o qual visa à consolidação de um banco de dados agronômicos com informações sobre a origem do material e o mantenedor no país (AVIANI, 2014; BRUCH; DEWES; VIEIRA, 2015). Salienta-se que, para ser protegida, a cultivar não precisa ser registrada, assim como pode ser registrada mesmo não sendo protegida (CARMO et al., 2019). O registro no RNC ocorre independentemente do direito do obtentor, podendo haver situações em que estas são produzidas e comercializadas sem o pagamento de royalties, quando a variedade vegetal, por exemplo, não é protegida pela LPC ou está em domínio público (BRUCH; DEWES; VIEIRA, 2015). Quando se tratar de sementes e mudas de cultivar protegida, o registro no RNC deverá ser requerido pelo obtentor ou por procurador autorizado, conforme o artigo $11, \S 5^{\circ}$ da LSM (BRASIL, 2003).

Qualquer espécie vegetal pode ser objeto de registro, exigindo-se para a inscrição, a depender da variedade, os ensaios de VCU ou de adaptação (BRUCH; DEWES; VIEIRA, 2015). O VCU corresponde ao "valor intrínseco de combinação das características agronômicas da cultivar com as suas propriedades de uso em atividades agrícolas, industriais, comerciais ou consumo in natura", a exemplo do potencial de rendimento, precocidade, reposta a insumos, qualidade de seus produtos, resistência a pragas, doenças e fatores ambientais negativos (BRASIL, 2003; CARMO et al., 2019). Realizados os ensaios de VCU, a inscrição é requerida pelos melhoristas do Programa via formulário eletrônico pela Plataforma CultivarWeb (MAPA, 2021).

A Portaria n. 349/2002 da UFRGS estabelece que os Testes de DHE e os ensaios de VCU das variedades obtidas pelos programas de melhoramento genético poderão ser executados pela Universidade ou por terceiros que venham a ser contratados. Conforme o Entrevistado, estes últimos são conduzidos pela UFRGS e demais instituições participantes da Comissão Brasileira de Pesquisa de Aveia (CBPA), de forma cooperativa, em diversas cidades da Região Sul do Brasil, variando conforme a disponibilidade da instituição e dos técnicos responsáveis. Após as 
análises de desempenho agronômico, que comparam a cultivar candidata ao registro com os caracteres de aveias já existentes no mercado, denominadas testemunhas, a Comissão reúne-se para a aprovação daquelas aptas a ingressar no mercado de sementes.

De acordo com o Entrevistado, a UFRGS realiza um ensaio de VCU preliminar, e os materiais que são identificados com qualidades superiores em $5 \%$ na média, em comparação a três das melhores variedades de aveia do mercado, são enviados para o exame técnico regional de VCU, seguindo, então para os ensaios brasileiros de $1^{\circ}$ e $2^{\circ}$ ano. Os exames são realizados conforme preveem as normas da CBPA, em três anos seguidos e, no mínimo, em 10 cidades. A cooperação das instituições vinculadas à CBPA reduz os custos com a elaboração das análises de desempenho agronômico, visto que a UFRGS conduz um dos ensaios, com cultivares próprias e recebidas das demais instituições, e obtém resultados de outros testes realizados com o seu material em cidades diversas. Garante-se, assim, que a nova espécie lançada comercialmente tenha comprovada adaptação em toda a região plantadora de aveia do país, não se limitando ao Estado do Rio Grande do Sul. Além disso, a comparação com as melhores variedades de cultivo do mercado assegura a efetiva qualidade dos materiais colocados à disposição dos agricultores.

O registro revela-se um importante instrumento para proporcionar maior garantia e segurança ao agricultor, evitando-se a aquisição de sementes e mudas desfavoráveis às condições de clima e ao solo do território brasileiro (CARVALHO; BIANCHETTI; REIFSCHNEIDER, 2009). Nesse sentido, é recomendada a aquisição de sementes e mudas certificadas, a fim de que sejam preservadas as características essenciais das cultivares (CARMO et al., 2019). Por fim, destaca-se que a inscrição no RNC é mais simplificada e menos custosa que o requerimento para a proteção.

\subsection{Transferência de Tecnologia de Cultivares de Aveia da UFRGS}

Com o registro no RNC, o potencial genético melhorado das cultivares pode ser distribuído aos agricultores por meio de sementes e mudas. A indústria de sementes é composta de melhoramento de plantas, multiplicação e comercialização/distribuição de sementes a agricultores (AVIANI, 2014; CARMO et al., 2019). Os obtentores são os agentes que viabilizam o desenvolvimento do melhoramento vegetal, visando a novas cultivares com as características que correspondam às demandas dos agricultores. Produzem as sementes genéticas. Os produtores de sementes, que podem ser pessoa física (próprios agricultores) ou pessoa jurídica, desempenham as atividades de multiplicação das sementes básicas, obtidas a partir da reprodução de semente genética, preservando sua identidade genética e pureza varietal (AVIANI, 2014; BRASIL, 2003; CARMO et al., 2019). Essa interação com os produtores pode ser celebrada como contrato de prestação de serviço, em que recebem a semente básica e multiplicam para o obtentor, responsável pela distribuição aos agricultores; como contrato de licenciamento, quando multiplicam e comercializam as sementes, nos estritos termos contratados, sujeitando-se ao pagamento de royalties ao obtentor sobre as vendas; ou mediante a permissão dos detentores do direito de exploração, ainda que sem contratos de licenciamento, para realização dos processos de multiplicação e comercialização com liberdade. Com a semente básica são produzidas as sementes certificadas de primeira $(\mathrm{C} 1)$ ou de segunda geração $(\mathrm{C} 2)$ para a distribuição no mercado, sendo que, a partir destas, a preservação do potencial genético original fica comprometida (AVIANI, 2014; CARMO et al., 2019). 
De acordo com o Entrevistado, as sementes genéticas das cultivares protegidas são reproduzidas anualmente pelo Programa, pois, caso não sejam preservadas, a variedade é extinta. A UFRGS transfere cerca de 20 a 30 sacas de sementes genéticas aos produtores de aveia para a produção de, aproximadamente, 8 a 10 hectares de semente básica, resultando, em média, 30 toneladas de sementes. Destas, o produtor de aveia mantém 10 toneladas e vende o restante como semente certificada de primeira geração aos agricultores e/ou cooperativas agrícolas. Em contrapartida pela comercialização da tecnologia, os produtores devem realizar a retribuição a título de royalties à Universidade, em percentual fixado sobre os valores auferidos com as vendas. Como a UFRGS não estipula uma quantidade específica a ser por eles comercializada, os montantes obtidos como contraprestação pelas vendas variam a cada ano, não podendo ser estimados previamente.

Para a inscrição do campo de produção de cultivar de aveia protegida no MAPA, são concedidas autorizações pela UFRGS, detentora do direito de propriedade intelectual sobre ela, aos agricultores, especificando a semente a ser cultivada, a categoria e o ano, em atendimento ao artigo 25 da LSM (BRASIL, 2003). Conforme diz o Entrevistado, essa é uma das formas de dar visibilidade ao trabalho promovido pela Universidade no desenvolvimento de cultivares.

A Política de Inovação da UFRGS elenca como atribuições do NIT, entre outras: negociar e gerir os acordos de transferência de tecnologia; opinar quanto à conveniência e promover a proteção das criações; acompanhar o processamento dos pedidos e a manutenção dos títulos de propriedade intelectual; desenvolver estudos de prospecção tecnológica e de inteligência competitiva, de forma a orientar as ações de inovação; desenvolver estudos e estratégias para a transferência de inovações; promover e acompanhar o relacionamento da UFRGS com organizações públicas e privadas, em especial para as atividades previstas nos contratos de transferência de tecnologia e de licenciamento e nos projetos de pesquisa, desenvolvimento e inovação (UFRGS, 2019). Assim, o NIT atua na elaboração e na gestão dos contratos de transferência de tecnologia e de licenciamento para outorga de direito de uso ou de exploração dos bens intangíveis da instituição. Nos casos de desenvolvimento conjunto com empresa, esta pode ser contratada com cláusula de exclusividade, dispensada a oferta pública, devendo ser definida a remuneração dos partícipes por instrumento jurídico. Em regra, as contratações envolvendo as cultivares de aveia são estabelecidas sem cláusula de exclusividade para a exploração, sendo firmadas direta e imediatamente pela UFRGS, representada pelo NIT. Após a celebração dos contratos referidos, deverão ser repassadas ao contratante os conhecimentos e as informações necessárias para a sua efetivação (UFRGS, 2019).

$\mathrm{O}$ bem imaterial da Universidade, portanto, pode ser objeto de licença, em que um terceiro faz uso, geralmente, em troca de uma remuneração paga ao titular de direitos, ou de cessão definitiva, nos casos de alienação do direito patrimonial, mediante pagamento único (ROOIJEN, 2011). A remuneração a título de royalties, na prática internacional, costuma ser fixada entre 3\% a 5\% sobre as vendas de sementes (ARAÚJO, 2010). Além dos custos de produção de novas variedades de plantas, o valor dos royalties deve considerar a estimativa de ganho genético decorrente do aumento da produtividade e da qualidade das cultivares ao longo de vários anos (SILVA et al., 2021). Referidos instrumentos jurídicos podem estabelecer multas por descumprimento de obrigações; causas de resolução contratual e o dever de restituição ou destruição do material propagativo; limitações ao uso e/ou controle da quantidade produzida 
da cultivar; exigências relacionadas às embalagens do produto ou à utilização da denominação ou do nome comercial e inspeções nas áreas de produção (GARCIA, 2011; ROOIJEN, 2011).

Para a consolidação da transferência dessa tecnologia, o relacionamento com os produtores é fundamental. De acordo com o Entrevistado, as primeiras interações foram estabelecidas nos denominados dias de campo, quando os melhoristas se deslocavam às cidades de cultivo de aveia e distribuíam cerca de $5 \mathrm{~kg}$ da cultivar desenvolvida aos produtores para o plantio em talhões. Agricultores da região eram convidados para conhecer a variedade plantada e receber orientações técnicas dos melhoristas do Programa, inclusive por meio de fôlder informativo das variedades. Também foi adotada a visitação dos produtores à Estação Experimental Agronômica da UFRGS para a apresentação das amostras de cultivares em desenvolvimento.

Interessados na aquisição das sementes de aveia realizam contato direto com os produtores iniciais ou com o próprio Programa, que divulga a listagem de todos os produtores que detêm sementes licenciadas. Segundo o Entrevistado, a credibilidade e a qualidade dos grãos obtidos com a cultivar de aveia da UFRGS são fatores que contribuem para a sua ampla aceitação no mercado, de modo que alguns produtores mantêm a parceria com a Universidade há mais de 30 anos. Entende, todavia, que a instituição poderia desenvolver estratégias de marketing para a transferência da tecnologia, sugerindo a elaboração de uma página de internet para a apresentação das novas variedades obtidas, com as respectivas características agronômicas $e$ fotografias, bem como a divulgação dessas informações ao sistema produtivo de aveia.

Atualmente, a UFRGS mantém o licenciamento de cultivares de aveia com 52 instituições, entre empresas ou cooperativas agrícolas. Em 2020, foi firmado o primeiro contrato com empresa norte-americana, interessada no cultivo do material (UFRGS, 2020). Nesses contratos de parceria para a produção e comercialização da tecnologia, estipulados por prazo indeterminado, incumbe ao produtor o pagamento de royalties a título de contribuição tecnológica, em geral, no percentual de $6 \%$ sobre o total apurado com a venda das sementes de aveia, com vencimento até o dia 31 de setembro de cada ano de comercialização. Segundo o Entrevistado, o montante auferido com a exploração é de, aproximadamente, $\mathrm{R} \$ 500$ a $\mathrm{R} \$ 600$ mil por ano. A gestão dos contratos compete ao NIT e, conforme prevê a Política de Inovação, fica autorizado o auxílio da fundação de apoio credenciada pela Universidade, que atua como interveniente nos contratos, na gestão financeira dos recursos, por meio de uma conta corrente específica para o projeto, em separado da conta corrente única da Universidade (UFRGS, 2019).

Por fim, o artigo $3^{\circ}$ do Decreto n. 2.553/1998 determina que, ao servidor da Administração Pública direta, indireta e fundacional, que desenvolver invenção, aperfeiçoamento ou modelo de utilidade e desenho industrial, será assegurada, durante toda a vigência da proteção, parcela do valor das vantagens auferidas pela entidade com a exploração da patente ou do registro, a qual não poderá exceder a um terço do valor total obtido (BRASIL, 1998). Por analogia, como forma de retribuição pela inovação desenvolvida e incentivo aos estudos na área de melhoramento genético, as Portarias n. 349/2002 e n. 493/2002 da UFRGS asseguram ao melhorista um terço do montante recebido pela Universidade com a exploração econômica das cultivares. Os dois terços restantes são repartidos entre o departamento, o centro ou o órgão auxiliar responsável pelo desenvolvimento da cultivar e o pagamento das anuidades para a manutenção da proteção (UFRGS, 2002a; 2002b). 


\section{Considerações Finais}

A partir dos resultados da pesquisa, verifica-se que os desenvolvimentos conduzidos pelo Programa contribuíram para a adaptação da aveia, espécie típica do clima temperado, às condições climáticas e ao solo brasileiro. Além disso, proporcionaram maior rendimento, qualidade industrial e precocidade ao ciclo do plantio até o florescimento, permitindo conciliar o cultivo de aveia, semeada no inverno, com as culturas de verão. Considerando que os estudos em melhoramento genético são de longo prazo, a dedicação e a permanência dos melhoristas na Universidade, característica comum em instituições públicas de pesquisa, aliadas à continuidade do grupo de pesquisa, existente há 47 anos, foram fundamentais para os bons resultados alcançados.

Em relação aos requerimentos de proteção e de registro de cultivares, observa-se que as rotinas estão consolidadas na Universidade, sendo realizadas pelos próprios melhoristas via preenchimento de formulários na Plataforma CultivarWeb. Tais atividades, em regra, seriam de incumbência do NIT, porém, em virtude dos conhecimentos técnicos necessários, optou-se por atribuí-las aos departamentos que desenvolvem novas variedades vegetais, conforme apontam as normativas internas. Salienta-se, também, a importância da colaboração da Universidade com as demais instituições participantes da CBPA, para fins de comprovação da adaptabilidade do material em toda a região plantadora de aveia do país e a redução de custos com a condução dos ensaios de VCU.

No campo da transferência de tecnologia, as ações integradas entre os melhoristas, produtores de aveia e agricultores, a exemplo da realização de dias de campo e de visitação à Estação Experimental Agronômica, destacam-se como importantes esforços para o estabelecimento de parcerias para a produção e a comercialização das sementes de cultivares. Não obstante, as estratégias para a disseminação da tecnologia desenvolvida podem ser ampliadas, aumentando a participação da Universidade no mercado de sementes. Ainda, no tocante aos royalties auferidos, identifica-se a necessidade de um papel mais ativo da instituição no controle das quantidades de sementes de aveia comercializadas, tendo em vista que são os próprios produtores que declaram o total apurado com as vendas, podendo haver distorções.

Por fim, cumpre apontar como limitação da presente pesquisa o fato de a Política de Inovação da UFRGS ser recente, datada de 2019, de modo que algumas das atribuições do NIT com vistas à transferência de tecnologia desenvolvidas na Universidade ainda não estão consolidadas na prática institucional e serão aperfeiçoadas com o tempo. Nesse sentido, em relação às cultivares, sugere-se maior atuação nas atividades de prospecção tecnológica e de inteligência competitiva em relação a outras variedades de aveia disponíveis no mercado, além do delineamento de ações de marketing comercial para a transferência das novas variedades obtidas junto ao sistema produtivo de aveia, principalmente por meio da implementação de uma vitrine tecnológica exclusiva para as cultivares lançadas comercialmente, com as respectivas características agronômicas e fotografias. 


\section{Perspectivas Futuras}

A partir do estudo de caso, sugere-se que trabalhos futuros possam ter o escopo de análise ampliado, proporcionando maior detalhamento sobre essa modalidade de propriedade intelectual sui generis, a partir das percepções de outros entrevistados, a exemplo dos produtores de sementes, agricultores, demais pesquisadores do Programa e membros do NIT da UFRGS. Além disso, considerando a importância do melhoramento vegetal de aveia para o setor agrícola do país, seriam relevantes estudos de âmbito regional ou nacional, envolvendo as instituições participantes da Comissão Brasileira de Pesquisa de Aveia.

\section{Referências}

ARAÚJO, José Cordeiro de. A Lei de Proteção de Cultivares: análise de sua formulação e conteúdo. Brasília, DF: Câmara dos Deputados, Edições Câmara, 2010. Disponível em: https:// www.researchgate.net/publication/45513707_A_lei_de_protecao_de_cultivares_analise_de_sua_ formulacao_e_conteudo. Acesso em: 23 nov. 2021.

AVIANI, Daniela de Moraes. Organizações coletivas para melhoramento vegetal: condicionantes de sua existência. 2014. 104p. Dissertação (Mestrado em Administração) - Faculdade de Economia, Administração e Contabilidade, Universidade de São Paulo (USP), São Paulo, 2014. Disponível em: https://teses.usp.br/teses/disponiveis/12/12139/tde-03122014-151349/publico/ DanieladeMoraesAviani.pdf. Acesso em: 23 nov. 2021.

AVIANI, Daniela de Moraes; MACHADO, Ricardo Zanatta. Proteção de cultivares e inovação. In: BUAINAIN, Antônio Márcio; BONACELLI, Maria Beatriz Machado; MENDES, Cássia Isabel Costa Mendes (org.). Propriedade intelectual e inovações na agricultura. Brasília, DF; Rio de Janeiro: CNPq; FAPERJ; INCT/PPED; IdeiaD, 2015. 384p. p. 225-243. Disponível em: https://www.embrapa. br/busca-de-publicacoes/-/publicacao/1047036/propriedade-intelectual-e-inovacoes-na-agricultura. Acesso em: 23 nov. 2021.

BRASIL. Decreto n 2.366, de 5 de novembro de 1997. [1997a]. Disponível em: http://www. planalto.gov.br/ccivil_03/decreto/1997/D2366.htm. Acesso em: 23 nov. 2021.

BRASIL. Decreto n. 2.553, de 16 de abril de 1998. Disponível em: http://www.planalto.gov.br/ ccivil_03/decreto/D2553.htm. Acesso em: 23 nov. 2021.

BRASIL. Decreto n. 10.586, de 18 de dezembro de 2020. Disponível em: http://www.planalto. gov.br/ccivil_03/_Ato2019-2022/2020/Decreto/D10586.htm. Acesso em: 23 nov. 2021.

BRASIL. Lei n. 9.456, de 25 de abril de 1997. [1997b]. Disponível em: http://www.planalto.gov. br/ccivil_03/LEIS/L9456.htm. Acesso em: 23 nov. 2021.

BRASIL. Lei n. 10.711, de 5 de agosto de 2003. Disponível em: http://www.planalto.gov.br/ ccivil_03/LEIS/2003/L10.711.htm. Acesso em: 23 nov. 2021.

BRASIL. Lei n. 11.105, de 24 de março de 2005. Disponível em: http://www.planalto.gov.br/ ccivil_03/_ato2004-2006/2005/lei/111105.htm. Acesso em: 23 nov. 2021.

BRUCH, Kelly Lissandra; DEWES, Homero; VIEIRA, Adriana Carvalho Pinto. A propriedade industrial: dupla proteção ou proteções coexistentes sobre uma mesma planta. In: BUAINAIN, Antônio Márcio; BONACELLI, Maria Beatriz Machado; MENDES, Cássia Isabel Costa (ed.). 
Propriedade intelectual e inovações na agricultura. Rio de Janeiro: Instituto Nacional de Ciência e Tecnologia - Políticas Públicas, Estratégias e desenvolvimento, 2015. p. 285-318. Disponível em: http://inctpped.ie.ufrj.br/pdf/livro/PI_e_Inovacoes_na_Agricultura.pdf. Acesso em: 23 nov. 2021.

CARMO, Flávia Lima et al. Cultivares - o que são, como se apropriar, como consultar. In: SANTOS, Wagna Piler Carvalho. Conceitos e Aplicações de Propriedade Intelectual. Salvador: IFBA, 2019. Coleção PROFNIT, v. II. 531p. p. 349-399. Disponível em: https://www.lume.ufrgs.br/ handle/10183/193427. Acesso em: 23 nov. 2021.

CARVALHO, Sabrina Isabel Costa de; BIANCHETTI, Luciano de Bem; REIFSCHNEIDER, Francisco José Becker. Registro e proteção de cultivares pelo setor público: a experiência do programa de melhoramento de Capsicum da Embrapa Hortaliças. Horticultura Brasileira, [s.l.], v. 27, n. 2, p. 135-138, abr.-jun. 2009. Disponível em: http://www.scielo.br/scielo.php?script=sci_arttext\&pid =S0102-05362009000200002. Acesso em: 23 nov. 2021.

CNS - CONSELHO NACIONAL DE SAÚDE. Resolução n. 510, de 7 de abril de 2016. Dispõe sobre a pesquisa em Ciências Humanas e Sociais. Brasília: Ministério da Saúde, 2016. Disponível em: http://conselho.saude.gov.br/resolucoes/2016/Reso510.pdf. Acesso em: 23 nov. 2021.

CORDEIRO, Fabio Lima; ROMEIRO, Luiz Antonio Soares. O uso próprio de sementes salvas e suas relações com o direito de propriedade intelectual dos obtentores vegetais brasileiros. Cadernos de Prospecção, Salvador, v. 13, n. 4, p. 957-973, set. 2020. Disponível em: https://repositorio.unb.br/ handle/10482/38105. Acesso em: 23 nov. 2021.

CUNHA, Elza Angela Battaggia Brito da. O direito sobre novas variedades vegetais. In: AVIANI, Daniela de Moraes; HIDALGO, José Antônio Fernandes (org.). Proteção de cultivares no Brasil. Brasília: MAPA, 2011. 206p. p. 23-26. Disponível em: https://www.gov.br/agricultura/pt-br/assuntos/ insumos-agropecuarios/insumos-agricolas/protecao-de-cultivar/informacoes-publicacoes/livroprotecao-de-cultivares.pdf. Acesso em: 23 nov. 2021.

FEDERIZZI, Luiz Carlos et al. Importância da cultura de aveia. In: LÂNGARO, Nadia Canali; CARVALHO, Igor Quirrenbach de (org.). Indicações técnicas para a cultura de aveia: XXXIV Reunião da Comissão Brasileira de Pesquisa de Aveia - Fundação ABC. Passo Fundo: Editora Universidade de Passo Fundo, 2014. p. 13-23. Disponível em: http://editora.upf.br/index. php/e-books-topo/44-agronomia-area-do-conhecimento/80-indicacoes-tecnicas-para-cultura-daaveia\#: : text $=\mathrm{A} \% 20$ aveia\% $20 \% \mathrm{C} 3 \% \mathrm{~A} \%$ 20cultivada $\% 20$ como,bovinos\%20de\%20leite $\% 20$ e 20 como. Acesso em: 23 nov. 2021.

GARCIA, Selemara Berckembrock Ferreira. Empresas de Sementes - Contratos, defesa nos tribunais. In: AVIANI, Daniela de Moraes; HIDALGO, José Antônio Fernandes (org.). Proteção de cultivares no Brasil. Brasília, DF: MAPA, 2011. 206p. p. 82-83. Disponível em: https://www.gov.br/agricultura/ pt-br/assuntos/insumos-agropecuarios/insumos-agricolas/protecao-de-cultivar/informacoespublicacoes/livro-protecao-de-cultivares.pdf. Acesso em: 23 nov. 2021.

GIL, Antônio Carlos. Como elaborar projetos de pesquisa. 6. ed. São Paulo: Atlas, 2017.

JUK, Yohanna Vieira; FUCK, Marcos Paulo. Appropriability Conditions and The Plant Variety Protection Law in Brazil. Journal of Technology Management \& Innovation, Universidad Alberto Hurtado, Facultad de Economía y Negocios, [s.l.], v. 15, n. 3, p. 74-82, out. 2020a. Disponível em: https://www.jotmi.org/index.php/GT/issue/view/vol15-issue3-2020. Acesso em: 10 nov. 2020.

JUK, Yohanna Vieira; FUCK, Marcos Paulo. Questões sobre proteção de cultivares no Brasil. Cadernos de Ciência \& Tecnologia, [s.l.], v. 37, n. 3, p. 1-14, 2020b. Disponível em: https://www.researchgate.net/ publication/345628507_Questoes_sobre_protecao_de_cultivares_no_Brasil. Acesso em: 23 nov. 2021. 
LEITE, Marcus Vinícius; CAMPOS, Silvana Rizza Ferraz. Aspectos legais de produção, comercialização e do uso de sementes no Brasil. In: AVIANI, Daniela de Moraes; HIDALGO, José Antônio Fernandes (org.). Proteção de cultivares no Brasil. Brasília, DF: MAPA, 2011. 206p. p. 93-96. Disponível em: https://www.gov.br/agricultura/pt-br/assuntos/insumos-agropecuarios/insumosagricolas/protecao-de-cultivar/informacoes-publicacoes/livro-protecao-de-cultivares.pdf. Acesso em: 23 nov. 2021.

MACHADO, Ricardo Zanatta. Elaboração de diretrizes de distinguibilidade, homogeneidade e estabilidade (DHE). In: AVIANI, Daniela de Moraes; HIDALGO, José Antônio Fernandes (org.). Proteção de cultivares no Brasil. Brasília, DF: MAPA, 2011. 206p. p. 121-142. Disponível em: https:/www.gov.br/agricultura/pt-br/assuntos/insumos-agropecuarios/insumos-agricolas/protecao-decultivar/informacoes-publicacoes/livro-protecao-de-cultivares.pdf. Acesso em: 23 nov. 2021.

MACHADO, Ricardo Zanatta; SANTOS, Fabrício Santana. Analisando a estabilidade. In: BRASIL. Ministério da Agricultura, Pecuária e Abastecimento. Secretaria de Desenvolvimento Agropecuário e Cooperativismo. In: AVIANI, Daniela de Moraes; HIDALGO, José Antônio Fernandes (org.).

Proteção de cultivares no Brasil. Brasília, DF: MAPA, 2011. 206p. p. 183-185. Disponível em: https://www.gov.br/agricultura/pt-br/assuntos/insumos-agropecuarios/insumos-agricolas/protecao-decultivar/informacoes-publicacoes/livro-protecao-de-cultivares.pdf. Acesso em: 23 nov. 2021.

MAPA - MINISTÉRIO DA AGRICULTURA, PECUÁRIA E ABASTECIMENTO. Instruções para a execução dos ensaios de distinguibilidade, homogeneidade e estabilidade de cultivares de aveia (Avena spp). Brasília, DF: MAPA, 2002.

\section{MAPA - MINISTÉRIO DA AGRICULTURA, PECUÁRIA E ABASTECIMENTO. Sistema}

CultivarWeb. Brasília, DF: MAPA, 2021. Disponível em: http://sistemas.agricultura.gov.br/snpc/ cultivarweb/. Acesso em: 23 nov. 2021.

MINAYO, Maria Cecília de Souza. O desafio do conhecimento: Pesquisa qualitativa em saúde. 9. ed. São Paulo: Hucitec, 2009.

PÁDUA, Juliano Gomes. Recursos genéticos aplicados ao melhoramento genético de plantas. In: AMABILE, Renato Fernando; VILELA, Michelle Souza; PEIXOTO, José Ricardo (ed.).

Melhoramento de plantas: variabilidade genética, ferramentas e mercado. Sociedade Brasileira de Melhoramento de Plantas. Brasília, DF: [s.n.], 2018. p. 25-32. Disponível em: https://ainfo.cnptia. embrapa.br/digital/bitstream/item/185597/1/Melhoramento-de-plantas.pdf. Acesso em: 23 nov. 2020.

PRIMAVESI, Ana Cândida; RODRIGUES, Armando de Andrade; GODOY, Rodolfo.

Recomendações técnicas para o cultivo de aveia. São Carlos: EMBRAPA Pecuária Sudeste, 2000. Disponível em: https://www.embrapa.br/busca-de-publicacoes/-/publicacao/45809/ recomendacoes-tecnicas-para-o-cultivo-de-aveia. Acesso em: 23 nov. 2021.

ROOIJEN, Silvia van. Exercício do direito do titular da proteção. In: AVIANI, Daniela de Moraes; HIDALGO, José Antônio Fernandes (org.). Proteção de cultivares no Brasil. Brasília: MAPA, 2011. 206p. p. 73-78. Disponível em: https:/www.gov.br/agricultura/pt-br/assuntos/insumosagropecuarios/insumos-agricolas/protecao-de-cultivar/informacoes-publicacoes/livro-protecao-decultivares.pdf. Acesso em: 23 nov. 2021.

SÁ, José Pedro Garcia. Utilização da aveia na alimentação animal. Londrina: IAPAR, 1995. Disponível em: https://www.bibliotecaagptea.org.br/zootecnia/nutricao/livros/UTILIZACAO\%20 DA\%20AVEIA\%20NA\%20ALIMENTACAO\%20ANIMAL.pdf. Acesso em: 23 nov. 2021. 
SANTOS, Nivaldo. O sistema de proteção das cultivares e desenvolvimento sustentável. In: DEL NERO, Patrícia Aurélia; PLAZA, Charlene Maria C. de Ávila. Proteção Jurídica para as Ciências da Vida: Propriedade Intelectual e Biotecnologia. São Paulo: Instituto Brasileiro de Propriedade Intelectual (IBPI), 2012. p. 173-200. Disponível em: http://superaparque.com.br/upload/20151014041058-protecao-juridica-para-as-ciencias-da-vida.pdf. Acesso em: 23 nov. 2020.

SILVA, Eduardo José de Souza et al. Estimative of royalties: appropriation of gains provided by innovations associated with plant breeding. Research, Society and Development, [s.l.], v. 10, n. 13, p. 1-16, 2021. Disponível em: https://rsdjournal.org/index.php/rsd/article/view/21497. Acesso em: 23 nov. 2021.

UFRGS - UNIVERSIDADE FEDERAL DO RIO GRANDE DO SUL. Decisão n. 16/2019, de 11 de janeiro de 2019. Porto Alegre: Conselho Universitário da UFRGS, 2019. Disponível em: http:// www.ufrgs.br/consun/legislacao/documentos/dec-ndeg-016-2019/view. Acesso em: 23 nov. 2021.

UFRGS - UNIVERSIDADE FEDERAL DO RIO GRANDE DO SUL. Faculdade de Agronomia Extensão. Porto Alegre: UFRGS, 2021. Disponível em: https://www.ufrgs.br/agronomia/joomla/ index.php/pesquisa/95-eea. Acesso em: 23 nov. 2021.

UFRGS - UNIVERSIDADE FEDERAL DO RIO GRANDE DO SUL. Portaria n. 349, de 8 de fevereiro de 2002. Porto Alegre: Reitoria da UFRGS, 2002a. Disponível em: http://www.ufrgs.br/ sedetec-intranet/pagina/legislacao/Portaria349-02.pdf. Acesso em: 23 nov. 2021.

UFRGS - UNIVERSIDADE FEDERAL DO RIO GRANDE DO SUL. Portaria n. 493, de 27 de fevereiro de 2002. Porto Alegre: Reitoria da UFRGS, 2002b. Disponível em: http://www.ufrgs.br/ sedetec-intranet/pagina/legislacao/Portaria493-02.pdf. Acesso em: 23 nov. 2021.

UFRGS - UNIVERSIDADE FEDERAL DO RIO GRANDE DO SUL. UFRGS licencia cultivar de semente de aveia para empresa internacional. Porto Alegre: UFRGS, 2020. Disponível em: http://www.ufrgs.br/ufrgs/noticias/ufrgs-licencia-cultivar-de-semente-de-aveia-para-empresainternacional. Acesso em: 23 nov. 2021.

UFRGS - UNIVERSIDADE FEDERAL DO RIO GRANDE DO SUL. Vitrine de Competências. Porto Alegre: UFRGS, 2018. Disponível em: https://www.ufrgs.br/vitrinedecompetencias/2019/04/16/ as-cultivares-da-ufrgs/. Acesso em: 23 nov. 2021.

\section{Sobre as Autoras}

\section{Patrícia Ziomkowski}

E-mail:patiziom@hotmail.com

ORCID: https://orcid.org/0000-0002-9955-0074

Mestra em Propriedade Intelectual e Transferência de Tecnologia para a Inovação, ponto focal IFRS, em 2021. Endereço profissional: Tribunal Regional do Trabalho da $4^{a}$ Região, Foro Trabalhista de Gravataí, RS, Rua dos Sabiás, n. 320, Bairro Diva Lessa de Jesus, Gravataí, RS. CEP: 94035-430.

\section{Kelly Lissandra Bruch}

E-mail:kelly.bruch@ufrgs.br

ORCID: https://orcid.org/0000-0003-2565-0790

Doutora em Direito pela Universidade Federal do Rio Grande do Sul em 2011.

Endereço profissional: Universidade Federal do Rio Grande do Sul, Faculdade de Direito. Avenida João Pessoa, n. 80, Centro Histórico, Porto Alegre, RS. CEP: 90040-000. 


\section{Giandra Volpato}

E-mail: giandra.volpato@poa.ifrs.edu.br

ORCID: https://orcid.org/0000-0002-2524-8868

Doutora em Engenharia Química pela Universidade Federal do Rio Grande do Sul em 2009.

Endereço profissional: Instituto Federal de Educação, Ciência e Tecnologia do Rio Grande do Sul, Campus Porto Alegre, Rua Coronel Vicente, lado ímpar, Centro Histórico, Porto Alegre, RS. CEP: 90030-041. 